\title{
Motivasi Pengembangan Pemasaran Krupuk Kulit
}

\author{
Daffanny Dicky Indraziz ${ }^{1}$ \\ Universitas Slamet Riyadi, Surakarta \\ e-mail:daffanny.dicky@gmail.com
}

\begin{abstract}
Abstrak
Melalui Kegiatan KKN-TEMATIK “MBKM Wujudkan Desa Bangkit” kita dituntut untuk mengamalkan ilmu pengetahuan, teknologi, dan seni. Kita diharapkan menjadi motivator dan fasilitator dari usaha pembangunan terutama di daerah pedesaan. Masyarakat dapat berbagi permasalahan yang ada dan mencari solusi dengan peserta KKN-TEMATIK "MBKM Wujudkan Desa Bangkit" Adapun tujuan atau target diharapkan dapat tercapai adalah mengembangkan pemasaran krupuk rambak kulit. Metode pelaksanaan kegiatan KKN-TEMATIK “MBKM Wujudkan Desa Bangkit"dilakukan dalam bentuk pemrosesan produksi hingga pemasaran. Hasil yang dicapai adalah pemasaran makin luas dan proses produksi semakin meningkat.
\end{abstract}

Kata kunci: pengembangan, produksi, pemasaran

\section{PENDAHULUAN}

Desa Sringin adalah desa di Kecamatan Jumantono, Karanganyar, Jawa Tengah, Indonesia. Desa Sringin terdiri dari 6 dusun (Ngemping, Tanggalan, Sringin, Geneng, Ngrombo, Ngemplak). Dukuhdukuh yang terletak di Desa Sringin, antara lain: Dewirejo, Durenan, Gedong, Geneng, Gondang, Jamprit, Kebak, Kepuh, Kotong, Krajan, Muntuk, Ngasem, Ngemping, Ngemplak, Ngrombo, Pencil, Sringin, Tanggalan, Tukuluh. Luas Wilayah Desa Sringin adalah 473,770 Ha.

Masyarakat Desa Sringin mayoritas bermatapencaharian sebagai petani, hal ini didukung oleh kondisi geografis desa yang terdapat banyak sawah dengan aliran sungai yang mudah dijangkau. Ada beberapa masyarakat Desa Sringin yang mengembangkan usaha rumahan, salah satunya adalah usaha rumahan abon, keripik tempe sagu, keripik singkong dan kerupuk rambak kulit sapi.

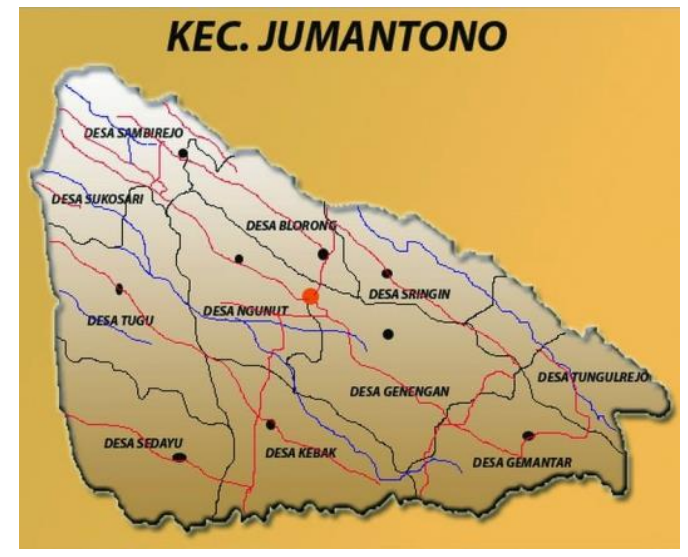

Gambar 1. Peta Kecamatan Jumantono

\section{METODE PENGABDIAN}

Dalam pelaksanaan program KKN-T ini, saya Tabitha Aurellia Dewanty mahasiswa Pelaksanaan program KKN-TEMATIK "MBKM Wujudkan Desa Bangkit" yang telah diseminarkan sebagai program final yang akan dilaksanakan selama kegiatan KKN-TEMATIK "MBKM Wujudkan Desa Bangkit" dan disesuaikan dengan jadwal yang telah disusun sebelumnya. Maka pelaksanaannya meliputi:

a. Pengembangan guna menambah wawasan agar mempunyai ide untuk segala kegiatan 
b. Produksi sebagai wadah untuk mengikuti kegiatan agar paham selama proses UMKM berjalan

c. Pemasaran sebagai target utama agar perkonomian selama pandemi meningkat

\section{HASIL DAN PEMBAHASAN}

Pembahasan terhadap hasil pengabdian yang diperoleh disajikan dalam bentuk uraian secara detail. Hasil pengabdian juga dapat ditampilkan dalam grafik, gambar, ataupun tabel. Metode penyajian grafik, dan tabel, dapat mengikuti format berikut ini:

\section{Persiapan dan Pembekalan}

Setelah melakukan observasi, maka dari itu kami mulai mensosialisasikan program yang ingin dilaksanakan dengan melakukan diskusi dengan Kepala Desa di Kantor Desa Sringin. Dengan demikian Kepala Desa selaku yang memberikan saran dan akses untuk program kami yang benar mengetahui program yang tepat sasaran kepada UMKM mikro dengan maksud mengembangkan pemasaran disertai inovasi rasa yang akan dilasanakan oleh KKN TEMATIK "MBKM Wujudkan Desa Bangkit" Universitas Slamet Riyadi Surakarta Tahun 2021 terkhususnya di wilayah Desa Sringin, Kecamatan Jumantono.

\section{Pelaksanaan}

Program KKN TEMATIK "MBKM Wujudkan Desa Bangkit” telah dilaksanakan bersama dosen pembimbing dan UMKM mikro yakni Krupuk Rambak Kulit Sapi yang tergabung di dalam kelompok 44 Dukuh Tukuluh, Desa Sringin, Kecamatan Jumantono, Kabupaten Karanganyar. Adapun kegiatan yang berhasil dilaksanakan dapat dilihat dalam alur kegiatan dan dokumentasi tersebut :

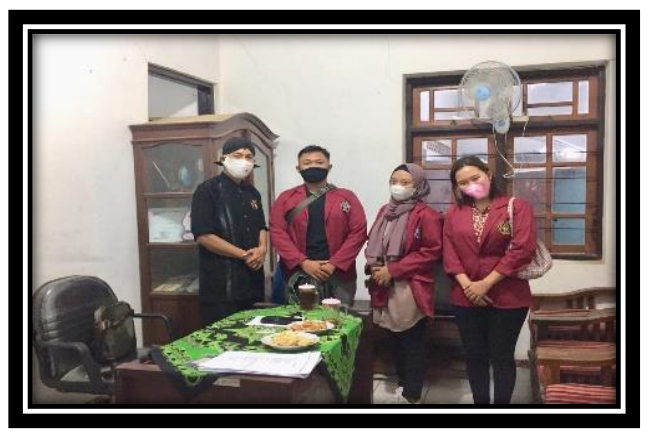

Gambar 2. Penerimaan Mahasiswa KKN-TEMATIK di Kantor Desa Sringin

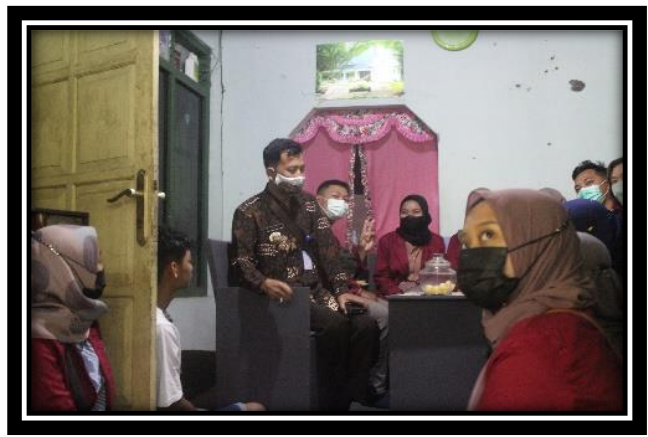


Gambar 3. Mengunjungi UMKM Krupuk Kulit sebagai pengenalan, perijinan dan survey 4.

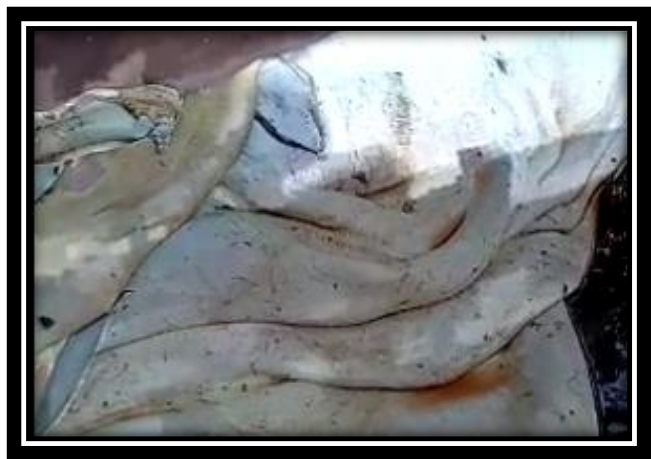

Gambar 4. Mulai proses produksi dengan mempersiapkan bahan utama yakni Kulit Sapi
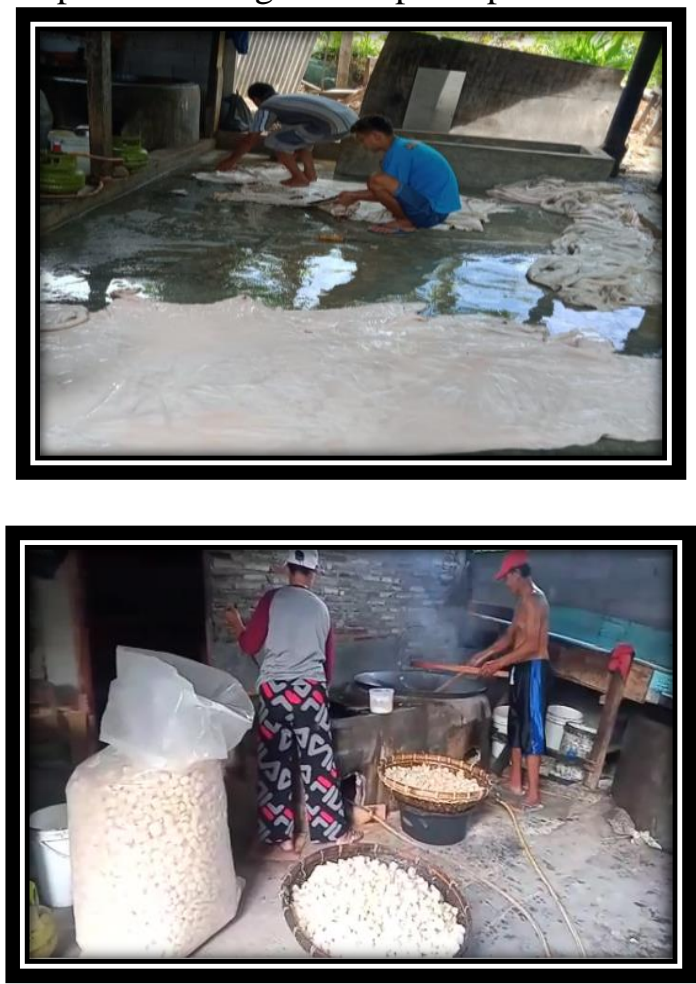

Gambar 5. Proses pengirisan kulit sapi, pemotongan, penjemuran, pelapuhan, penggorengan dan penirisan

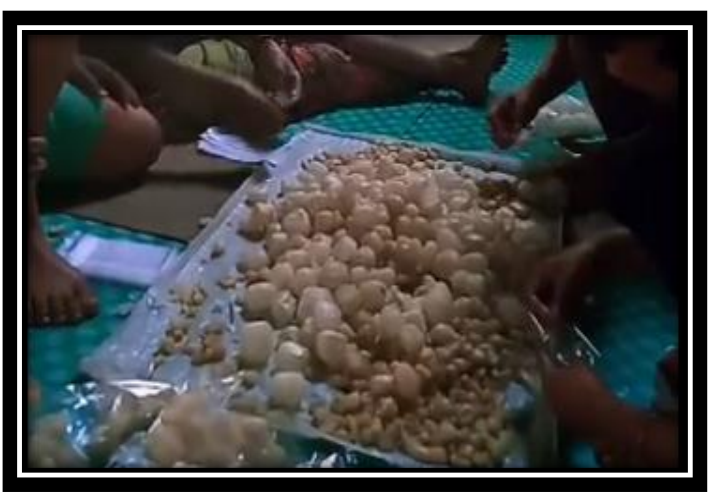




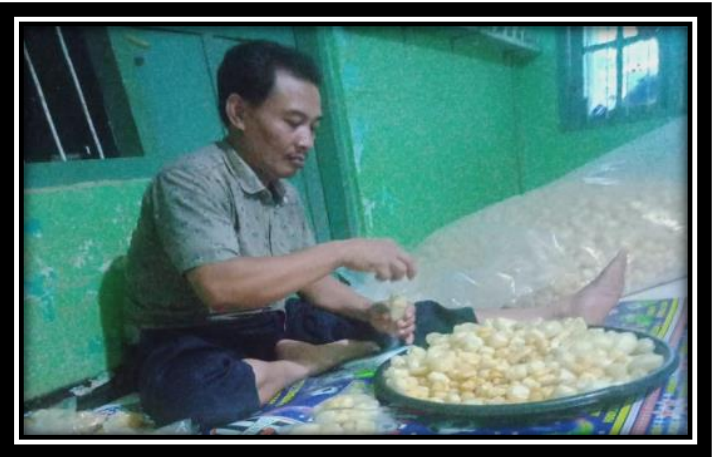

Gambar 6. Proses penganginnan disertai pemberian inovasi rasa dan pengemasan
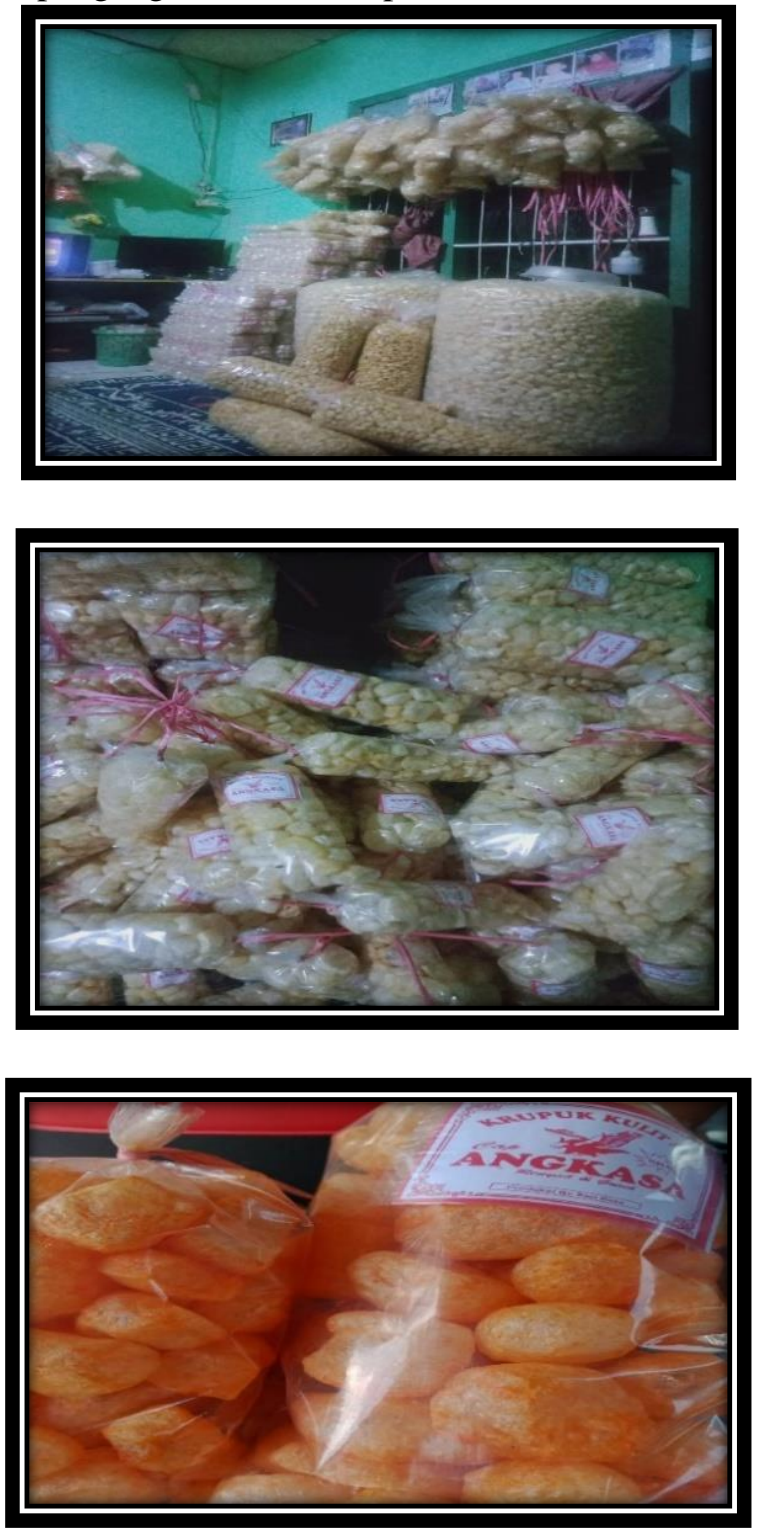

Gambar 7. Pengembangan pemasaran dilakukan secara online

\section{Monitoring dan Evaluasi}

Dalam program kerja ini yang sudah direncanakan dapat dilaksanakan dengan baik sesuai jadwal yang telah ditentukan tetapi disadari dalam pelaksanaannya masih terdapat kekurangan yang perlu dibenahi dimasa yang akan datang. Keterbatasan sinyal yang paling utama karena di masa pandemi saat ini pemasaran melalui offline bagi UMKM mikro sangatlah sulit. 


\section{SIMPULAN}

Berdasarkan hasil pelaksanaan pengabdian, maka beberapa kesimpulan dari kegiatan ini adalah: (a) program KKN-TEMATIK "MBKM Wujudkan Desa Bangkit" sangat didukung pemerintah sebagai program pengabdian yang membantu pemerintahan dalam pemberdayaan masyarakat; (b) program KKNTEMATIK "MBKM Wujudkan Desa Bangkit" menjadi sarana untuk melakukan pengabdian kepada masyarakat; (c) program KKN-TEMATIK "MBKM Wujudkan Desa Bangkit" menjadi sarana potensi daerah yang belum dikelola dengan baik.

\section{SARAN}

Adapun saran dalam pelaksanaan program KKN-TEMATIK "MBKM Wujudkan Desa Bangkit" adalah keberhasilan pelaksanaan program KKN-TEMATIK "MBKM Wujudkan Desa Bangkit" harus didukung penuh oleh pemerintah dan unsur masyarakat.

\section{UCAPAN TERIMA KASIH}

Penulis mengucapkan terima kasih kepada Tuhan Yang Maha Esa Allah swt. yang telah memberi kelancaran terhadap keberhasilan pengabdian ini.

\section{DAFTAR PUSTAKA}

Direktorat Penelitian dan Pengabdian Kepada Masyarakat Direktorat Jenderal Pendidikan Tinggi Kemendikbud RI. 2013. Pedoman Penelitian dan Pengabdian kepada Masyarakat Edisi IX.

Kementrian Pendidikan dan Kebudayaan. Panduan Program KKN-PPM, Direktorat Penelitian dan Pengabdian Kepada Masyarakat, Dirjen DIKTI 